\title{
Study-Abroad Experiences of Two South Korean Undergraduate Students in an English-Speaking and a Non-English-Speaking Country
}

\author{
Miyoung $\operatorname{Nam}^{1}$ (D)
}

Published online: 9 March 2018

(C) The Author(s) 2018. This article is an open access publication

\begin{abstract}
Benefits of the study-abroad (SA) experience have been reported in many studies. However, most prior studies on EFL students' SA experiences track students in relatively short ESL programs during school vacation months. In addition, EFL learners' SA experiences in nonEnglish-speaking countries, where English is not the L1, remain underexplored. Applying case study methodology and gathering data from monthly reports during SA, and pre- and post-SA interviews, this study aimed to investigate SA experiences of two South Korean undergraduate students in two different SA environments with respect to the impact of the participants' choice of SA destination on the SA experience and the participants' interactions with the SA environment. The SA destination had a significant impact on the student in Finland. Dealing with a third language and failing the language course, the student in Finland had to leave the program earlier than planned. The student in Australia took great advantage of social networks she established through diverse venues, which enriched her SA experience and facilitated her learning. It is particularly meaningful that the present study broadened the scope of SA research, as it extended the context to "other" regions.
\end{abstract}

Keywords Study abroad - Social network . Non-English speaking context

Miyoung Nam

nammg@ynu.ac.kr

1 Graduate School of English Education, Yeungnam University, 280 Daehak-ro, Gyeongsan-si 38541, Gyeongsangbuk-do, South Korea

\section{Introduction}

Many studies emphasized the importance of student interactions with native speakers (NSs) in L2 learning (Dewey et al. 2013; Magnan and Back 2007; Segalowitz and Freed 2004), and the study-abroad (SA) context is known to offer "greater access to NSs and more varied opportunities to use the target language as a tool for exchanging information and participating in social and interpersonal functions" (Hernandez 2010, p. 601). SA experiences are often believed to be ideal for the target language and culture learning, and benefits of SA programs have been reported in many studies (Allen 2013; Batstone 2002; Duff 2007; Hernandez 2010; Isabelli-Garcia 2006; Kang 2014; Magnan and Back 2007; Mora and Valls-Ferrer 2012; Sasaki 2007; Yang and Kim 2011).

A large number of South Korean students seek opportunities to study abroad around the world in both Englishspeaking and non-English-speaking countries every year. According to the educational statistics released by the Korean Educational Development Institute, in 2015 alone, 214,696 South Korean students went abroad to pursue degree or non-degree programs. Not much research on Korean students' SA experiences exists, however (Choe 2013), and most studies on L2 students' SA experiences were conducted in relatively short ESL programs. In many cases, students went abroad during vacation months in the SA context. Moreover, little research exists on SA experiences of EFL learners in non-English-speaking countries, where English is neither the native tongue nor an official language. In addition, not all SA applicants get their choice of placement, and worse, some applicants enroll in programs that may not match their needs and interests.

In order to fill this gap in SA research, the present qualitative case study attempted to explore SA experiences 
of two South Korean undergraduate students participating in two different SA programs as exchange students in two different countries: one in Australia and the other in Finland, and they were placed in undergraduate content courses where they could mingle and study alongside local students during the regular academic year of 2014-2015. Through the participants' detailed monthly reports on their SA experiences and pre- and post-SA interviews, this study aimed to investigate "the particularity" (Stake 1995, p. 39) of each case and further understand the participants' complex interrelationships with their unique SA environment.

\section{Literature Review}

\section{Study Abroad}

SA experiences are considered as opportunities to study the L2 while immersed in the L2 culture and exposed to the constant availability of the L2. Some of the positive results of SA include an enhanced speaking ability as well as increased classroom interaction, reduced foreign language classroom anxiety, and improvement in L2 writing quality and fluency.

Kang (2014) investigated 60 Korean university students participating in eight-week SA programs in the US, the UK, or Canada during their summer vacations. The context of the study was a non-academic ESL-type of SA program in English-speaking countries. The students benefited from SA experiences in willingness to communicate and speaking abilities, and their classroom interaction also increased after SA. Another large-scale study on Korean students by Thompson and Lee (2014) centered on delineating the relationship between English language anxiety and SA. About 148 EFL learners from two universities in Seoul participated in the study. The participants selfassessed their time abroad ranging from never to more than a year abroad and also answered a survey online. While SA was found to help reduce EFL students' foreign language classroom anxiety, sociocultural aspects of SA experiences need to be taken into account due to the diversity of SA experiences and the uniqueness of each SA experience.

In her longitudinal study on 11 Japanese students' L2 writing development at a university in Japan, Sasaki (2007) compared the effects of SA experiences on L2 writing between the ESL and the EFL groups. The ESL group with SA experiences showed more improvement in L2 writing quality and fluency than the EFL group. Although six out of the seven students in the ESL group reported that their low English proficiency made them feel "alienated, inferior, or nervous" (p. 614), they gradually became more motivated and confident during their time abroad. This change in their attitude was found to be attributable to making friends with English-speaking and foreign classmates, highlighting the need to look closely at how L2 students engage in their SA environments.

\section{Social Interactions in Study Abroad}

Some studies explored how L2 students interacted with their SA environments (Duff 2007; Hwang 2009; Tanaka 2007; Tanaka and Ellis 2003; Yang and Kim 2011). For example, Duff (2007) studied a group of Korean undergraduate students in mainstream content courses socializing into their local Canadian community of practices. Founded on community of practice (Lave and Wenger 1991; Wenger 1998), Duff (2007) examined "the processes that facilitate or obstruct learners' increasing legitimacy, participation, and identities within their new learning communities" (p. 325). The findings revealed that the students had "limited (meaningful) access to local Englishmedium social networks and communities" and due to "pressures of in-group Korean-conformity and affiliation" (p. 316) they had to resort to Asian, non-AngloCanadian groups, Generation 1.5 Korean-Canadians for example, to practice English with. Generation 1.5 in Duff refers to "children who immigrated as children or young adolescents, received some or all of their schooling in the immigrant context, and typically are quite fluent in oral English" (p. 316). The role of Generation 1.5 KoreanCanadians in Duff is parallel to the role of local Philippine tutors in Yang and Kim (2011) as these two particular groups helped facilitate Korean students' socialization into their respective local communities. Yang and Kim in their study of L2 learning beliefs in SA contexts examined two Korean students' learning paths, one in the US and the other in the Philippines, and how their learning paths diverged. While the English-speaking context for the student in the US was limited to the ESL program, the student in the Philippines successfully expanded the Englishspeaking context to the local community thanks to tutors, who mediated the learning trajectory of the particular student toward the local community. Yang and Kim emphasized the meaningful interactions in the SA context, and they pointed out "SA participation per se does not guarantee a high level of personal L2 success" (p. 331).

Building rapport with such Asian groups or local tutors, however, does not commonly occur for L2 students, let alone with local NES students. For example, Tanaka and Ellis (2003) and Tanaka (2007) reported limited contact with English outside the language classroom. The former described the SA program as "a Japanese college overseas" (p. 81), and in the latter the students tended to stay alone in their rooms or spent time mostly with their Japanese friends. This is what usually happens when L2 
students of the same L1 take part in SA programs as a group, and it could also promote more use of their L1 as was found in Shvidko et al. (2015).

Benefits of social networks were reported in learning other languages as well. The highest achieving student in Isabelli-Garcia (2006) on a semester-long Spanish language program in Argentina was the one who gained immediate access to a social network through a friend of a friend, and the ready-made network made it possible for him to actively engage in a variety of social activities. Dewey et al. (2013) also showed that one of the most common strategies American students used to form social networks in learning Arabic in Jordan and Egypt was "meeting new friends through existing friends" (p. 269), and the data provided by Dewey et al. revealed that about $23 \%$ of the friends of the students were connected through native-speaker friends or acquaintances.

Most prior studies reviewed on EFL students' SA experiences were conducted over the vacation months when schools were not in session, which in turn limited L2 students' interaction with local students and therefore might have hindered their efforts to socialize into the local academic community. Interactions with tutors (Yang and Kim 2011) or interactions created as a result of language exchange (Dewey et al. 2013) are generally very limited in SA contexts, and more research is needed to describe diverse cases of L2 students' interaction in the SA environment during a regular academic year. In addition, L2 students' SA experiences in non-English-speaking countries, where English is not the L1, remain underexplored. In order to address these issues, two cases of academic SA were studied, one of which took place in a non-Englishspeaking country. Academic SA in this study is defined as "an organized exchange of students between participating universities, the aim of which is integration into the student's regular education through a cross-registration system and the home university's recognition of the student's studies at the exchange university" (Ahn 2014, p. 107). The uniqueness of individual cases was examined based on the two following questions:

1. How does the participants' choice of SA destination affect their SA experience?

2. How do the participants interact with the SA environment?

These two questions were aimed to reflect on the significance of the SA destination selection process by extending the SA context to "other" countries and to shed additional light on the benefits of diverse social interactions in the SA context.

\section{Methodology}

\section{Participants and Settings}

Two students enrolled in an English composition course that the author taught at a university located in Gyeongsan, South Korea were asked to participate in the study upon finishing the spring 2014 semester. A lot of students, mostly English majors, in the class showed interest in studying abroad, and four out of 40 students, in fact, had applied for SA programs. This study focused on two students on their academic SA (SA hereafter) as exchange students for the academic year 2014-2015. The names presented in this study are pseudonyms. Yujin was in her third year of study in English Language and Literature, double majoring in International Studies. Inyoung was a double major in Chinese and English Language and Literature, and at the time of the data collection, she was in her fourth year.

At the time of the first interview prior to SA, the participants had decided on where to go for their SA: Yujin to a university in Australia and Inyoung to a university in Finland. According to the advertisement on the studentexchange program for the 2014-2015 academic year, there were 31 openings for programs in English-speaking regions: the US, England, Canada, Australia, and Hong Kong, while 48 openings available at seven universities in six non-English-speaking countries: the Netherlands, Finland, Turkey, Mexico, Germany, and France. English language requirements for all programs in English-speaking regions and most programs in non-English-speaking regions were 80 in TOEFL iBT or 6.0 in IELTS, or higher, although a couple of programs in non-English-speaking countries also accepted TOEIC scores of 750 or above.

Yujin chose Australia because she wanted to attend a 1-year-long program. The other two 1-year programs were left out, one for being intensive ESL and the other known for having many Korean exchange students on campus. This Australian university located in Adelaide offers over 400 undergraduate and postgraduate degrees and has a student enrollment of about 20,000. In the case of Inyoung, she excluded programs not conducted in English or that were designated for certain majors only. All programs in English-speaking countries were also left out because her TOEFL score did not meet the requirement. These factors narrowed her choice down to a university of applied science in Finland with about 8000 students offering bachelor's programs in service business management, business information technology, nursing, social services, security management, and restaurant entrepreneurship. It did not have programs in her major. 


\section{Data Collection and Analysis}

As a well-established research methodology, Stake (1995) defines qualitative case study as the "study of the particularity and complexity of a single case, coming to understanding its activity within important circumstances" (p. $\mathrm{xi}$ ), and Merriam (1998) describes it as particularistic, descriptive, and heuristic. By being heuristic, Merriam observed that "case studies illuminate the reader's understanding of the phenomenon under study" (p. 30). Under the social-constructivist and sociocultural framework, in order to gain an in-depth understanding of the participants' dynamic interactions in each SA environment of their own choice, a case study was employed. Observations, interviews, and documents are usually used as data-gathering tools in a qualitative case study. However, since it was not possible for the author to observe the participants and the contexts abroad in person, observations were replaced with monthly individual reports.

Monthly reports mostly written in Korean were sent via email from the participants during their time abroad and served "as substitutes for records of activity that the researcher could not observe directly" (Stake 1995, p. 68). In order to study the complexity and particularity of each case, the participants were asked to describe in writing what happened in and out of the classroom between the reports. The questions appearing on the reports were uniquely developed to each participant, and the follow-up questions were tailored to the previous reports to further examine what the participants were experiencing in their unique SA environments. The reports were sent as a file attachment on a monthly basis and usually were one to two pages in length. Documents on the SA program information were also collected, and for more information, the author contacted the center supervising all SA programs at the home university.

The author had two interviews with each participant. The first interview took place prior to SA to gather the participants' personal information and their SA program information. They also shared their goals for SA and explained why they chose their final SA destination. The second interview after they returned from SA aimed to clarify some of the questions that needed additional explanation, to better understand the meanings underlying the participants' thoughts and actions described in their monthly reports, and to have them reflect upon their overall SA experiences. The participants illustrated their views and evaluations on SA including their SA destinations. They were also asked to draw a detailed graphic portraying the social networks they had formed during their sojourn abroad. Conducted in Korean, the interviews lasted about an hour for each participant. When the excerpts from their monthly reports and interviews were translated by the author into English for the purpose of publication, the participants were asked to review them for accuracy.

The author adopted the constant comparative method of data analysis (Glaser and Strauss 1967) and began with coding notable incidents from the participants' monthly reports, which were then analyzed with respect to the interview data and the documents. Through the process of comparing incidents relevant to each category, integrating categories, and narrowing down the scope of the categories, two major themes emerged. In the case of Inyoung, the SA destination of her choice seemed to have a significant impact on her during her entire stay abroad, while the most recurring theme in the case of Yujin was social networks. Findings of this study will be presented around these two themes.

\section{Findings}

\section{Inyoung's Choice of a Study-Abroad Destination}

Inyoung's TOEFL score, which did not meet the minimum required score for programs in English-speaking regions, narrowed her choice down to programs in non-Englishspeaking regions, and she opted for a university in Finland, hoping to take advantage of the location to travel in and around Europe. Prior to SA, she registered for Organization Communication, Business Management in the Hospitality Field, Event Management, and Basic Finnish courses. Without enough knowledge of the program but with vague interest, she registered for the courses based solely on the course titles she received through the international center at her home university, which contained minimal information about credits, lecturers, and brief notes such as online implementation or team work. No detailed course descriptions were provided.

One major problem Inyoung encountered in SA was language. In her September report, she pointed out unfamiliar English accents of professors, which impeded her understanding of lectures, and also her Finnish classmates speaking in their native language during class among themselves instead of English. Of particular note in her first report was her experience in the first class meeting of Event Management. Inyoung explained what happened:

We were introducing each other to the class in pairs, and I was the only Asian in that class. The one who got paired with me, she was an Italian, suddenly moved to a different seat, so I had to ask students sitting behind to let me in their group. It was very embarrassing, and I couldn't say a word.

She was able to finish the activity "safely," and she remarked that the students in the class seemed very 
straightforward when it came to grades. In her October report, she described the local students as "just busy with their life" and wrote "It's just like me. I did not hang out with those foreign students outside classrooms at home, either." Inyoung further added later in the interview "who would want to take a risk with grades by working with someone who is not even good at communicating, to say nothing of content knowledge."

In addition, most of the exchange students were from Europe, and according to Inyoung, they did not seem to have much difficulty in the language. EFL courses were not provided for foreign students as it is in the case of Englishspeaking countries. One of the courses required students to produce four essays, one every other week, each of which had to be at least 10 pages in length. An hour-long video on YouTube on how to write an essay was the only resource she could depend on, and she said no other writing aids were available. She seemed overwhelmed with the assignments.

Inyoung's choice of SA destination presented her with another problem, failing the Basic Finnish course. Learning Finnish was not even close to her SA goals in the first place, but she expected it to be a place for meeting with other exchange students. Failing this course meant she would be unable to complete the required credit hours in time for graduation at her home university if she remained in Finland for the second semester. She had no choice but to leave earlier than she had originally planned.

In the interview, she said "I applied for this exchange program in the fourth year, and I think it's a bit late. It might have been better if I had come earlier. A lot of students postpone applying for those study-abroad programs because they think their language is not quite ready." This may be attributable to the fact that failing to manage course credits while in study abroad in her fourth year certainly added more pressure for time, which inevitably led to her leaving the SA program earlier than planned. She also remarked in the interview "if I had been better informed of the courses, I would have not taken some of the courses." The university and the program Inyoung attended were so specialized in certain majors that it might not have been the right choice for Inyoung in the first place.

The socialization path that Inyoung explored seemed individual and independent, as she had to plow through the SA trajectory on her own. Moreover, without proper assistance from the local academic community, it seems that she did not obtain the best results for her efforts made in the process. Nevertheless, there were some positive results. She mentioned in the interview "I gained confidence in communicating with foreigners. I think I will be able to talk without hesitation and not feel afraid because I had to do many things by myself with no help while I was in Finland." There were four other Korean exchange students studying on the same campus, but she rarely saw them because they were in different courses. Not being surrounded by the students of the same L1, she had to figure things out on her own, such as renting a place to stay, asking Finnish classmates for course information, and socializing with other exchange students, thereby laying a foundation for increased confidence. In addition, carrying out group activities for courses provided a venue for interactions with Finnish classmates. In the case of Event Management, which lasted all day from 9 a.m. to 4 p.m., she spent a lot of time with classmates organizing an event throughout the semester, performing many activities while completing the event. However, the very particularity of her SA destination forced her to shorten her SA sojourn to one semester, and her L2 practice in the SA environment was very much limited to the classroom environment and among exchange students.

\section{Yujin's Social Networks in the Study-Abroad Environment}

Diverse opportunities for social interactions were available to Yujin in her English-speaking SA environment from the beginning, and she was actively involved in the social networks she established via various venues. It seemed that in and out of classrooms, she was making an effort to actively socialize into the community. For example, she attended "Culture Night" every Friday, an event provided by the university for experiencing different cultures, and through which she took tours of the campus and famous places in the city. She also tried to participate in a variety of events that the dormitory offered, as well as local events advertised in her first semester dormitory. Participating in such events as local marathons, Pilates, or festivals not only broadened her social networking, but it also helped her learn the culture and socialize into the local community. She wrote:

At the local events, which I try to go to about twice a week, I have so-called "everyday" conversations with people, and I learn about Australian culture, their ways of thinking and life, and Australian English. For example, I discovered that they say "No worries" more often than "Thank you" and they also use "mate" a lot. I heard that they started using the word "mate" to promote the sense of unity after being federated. I also hear a lot of British expressions. (December, 2014).

The social networks that Yujin established during her SA sojourn were categorized into three groups: one through a Chinese course; another from her part-time job at a Japanese restaurant; and the other passed down from a 
former Korean exchange student. Yujin enrolled in the Chinese course because she figured having learned the language back home could alleviate her study-load, which, unlike the case of Inyoung who had stress of learning a completely new language, left Yujin more room for social interaction. The one she built through this Chinese course included three Australian-born Chinese students. Yujin seemed to find cultural familiarities with those Australianborn Chinese students who showed particular interest in Korean culture. She said she often gathered with this group of Australian-born Chinese students outside classroom to eat out or have coffee. Except for this particular student group from the Chinese course, it seemed difficult to build relationships with L1 Australian students outside the classroom. She wrote:

I have some Aussie friends, but the cultural difference is something that we cannot ignore. In fact, those Aussie friends are mostly the ones with Asian backgrounds. We share interests and they are interested in Korea, which makes communication easy. (May, 2015).

In addition to the Chinese course, she registered for Shakespeare, Asia and the World, and an ESL course in the first semester. In the second semester, she took Foundations of Linguistics, International Political Economy, Psychology, and Chinese 2 in continuation of the Chinese course of the previous semester. When signing up for courses, she contemplated their relevance to her majors first and then her personal interests as in the case of Shakespeare. She also registered for Psychology and Chinese, "easy" courses as she described, based on the course information gathered through her social networks. Taking these courses seemed to reinforce her content knowledge and also help improve her English.

In her report on January 30, Yujin mentioned that she began to work part-time at a Japanese restaurant from late December and wrote "it is more fun than I thought and the staff are all my age. I made friends with them and also there are many Aussie people who come into eat. It helps my English. I can also save some money for traveling." She found the job from a website shared by the local Korean community to share information on housing, jobs, items for sale, local events, etc. The socializing at her work lasted until April when she quit the job as she decided to spend more time on coursework. This part-time working environment was another venue for her to learn everyday Australian English and culture. Yujin's well-prepared English as well as being in the English-speaking SA environment probably made this experience possible.

It was of particular note that Yujin mentioned a student who was from the same home university and was about to leave upon finishing her SA at the Australian university when Yujin arrived. Yujin wrote in her first report:

Thanks to her I could start my life here easily. Before leaving, she introduced me and Hyunju [another Korean exchange student] to many of her friends that she had made here. I think a lot of them being very friendly toward Korea helped set the stage for more communication for me.

The ready-made network passed on to Yujin from this former exchange student was mostly composed of exchange students from Asia. These students of different L1s formed a unique community of their own in the SA environment. Being with these exchange students of different L1s, Yujin said she used English in more than $70 \%$ of her communication even with Hyunju, another Korean exchange student. While temporary in nature, newcomers were filling in for departing students, and their relationships were extensively intertwined with "friends of friends" as she illustrated in the interview. Yujin's social networking, as a result, did not leave much room for L1 use in communication but fostered various opportunities for L2 use. Yujin reflected upon her SA experience in the interview as follows:

It was great to know a little more about Australia by communicating with local people and experiencing their culture during my stay. It would have never been possible without the exchange student program. It was hard to study, and I felt limited sometimes, but looking back on those days I did my best so there is no regret. I feel that I've grown up so much.

Rather than limiting her interactions to the classroom, Yujin actively attempted to create more opportunities for interaction through diverse venues outside the classroom.

The only problem Yujin encountered during her SA sojourn was different teaching and learning methods. At the beginning of her SA, she reported struggles with tutorial sessions, where students had debates and group discussions for courses. In her second and third reports, she wrote:

Two language courses are fun and I can kind of catch up with those courses without much difficulty. However, when it comes to the other two, Asia and the World and Shakespeare, I get nervous during the tutorials because I have to talk, and that gives me stress. I' $m$ fine in lectures, and the professors use PPTs, which helps a lot, but with other students, when they speak, it's hard to understand them, and so I have to pay more attention to them. (September, 2014). 
I think the problem is that I was not used to in-class discussion because in Korea classes are mostly lectured-based. In tutorials, professors make all students talk here. In the Asia and the World class, in particular, the professor points to every single student to talk and gives feedback. It's okay to talk about my own opinions or present assignments, but when it comes to discussion, it's still difficult to make prompt counterarguments. I can't do that even in my own language, and not to mention in English. (October, 2014).

Even though she expressed difficulty with tutorials in the beginning, being very active and exploratory, she worked hard to become engaged in the tutorials rather than just be physically present. Toward the end of the first semester, she became more stable and comfortable and started to enjoy exploring the SA environment. She wrote that she would look for a new place to stay outside the dormitory, prearranged through the international center at the home university, and she also started looking for a part-time job. She wrote in her report on April 17, about a month after the second semester had begun in 2015:

I am taking two second-year courses so I have to spend more time studying because there are more materials to read and also I have to prepare for tutorials... I think I am doing better in lectures and tutorials this semester. I had a hard time understanding tutorials last semester, but this semester I think I am catching up with the students' debating. It made me think that I did not waste time here.

Yujin's hard work resulted in good grades and increased confidence in using English, and most of all, her multiple social interactions seemed to enable a more natural use of English.

\section{Discussion}

The present study attempted to investigate SA experiences of two South Korean undergraduate students in two different SA environments with respect to the impact of the participants' choice of SA destination on SA experience and the participants' interactions with the SA environment. Findings showed that the uniqueness of each SA program resulted in the participants' different SA trajectories, which calls for a strong need to offer SA programs that best fit the students' needs and interests as the case of Inyoung revealed in particular.

Yujin, immersed in a student-exchange program in an English-speaking country, seemed to expose her to more diverse circumstances for language and culture learning compared to Inyoung in a non-English-speaking country. Inyoung had to singlehandedly cultivate environments to practice English mostly by taking content courses and participating in group assignments for the courses. Inyoung's choice of SA destination seemed to affect her SA experience both negatively and positively. First of all, the program she opted for was loosely, if at all related to her majors. She had to deal with all new courses at the SA context with no prior content knowledge. On top of that, dealing with a third language, Finnish, added more of a burden, and failing Basic Finnish forced her to leave the program earlier than planned. On the positive side, in the process of pioneering the SA environment on her own, Inyoung was made to use English in order to figure out immediate problems, and these practices contributed to her gaining confidence in using English. If Inyoung had stayed for another 6 months as she had originally planned, her socialization path may have developed very differently.

The fact that the programs in English-speaking countries are generally preferred over programs in other regions and therefore have more students with language learning needs may explain the comparatively richer English-learning opportunities developed and offered by the host universities in English-speaking countries. In fact, most researches on SA experience of EFL students (e.g., Hwang 2009; Kang 2014; Sasaki 2007; Tanaka 2007; Tanaka and Ellis 2003; Yang and Kim 2011) were conducted in Englishspeaking countries or in countries like the Philippines, an Outer Circle country, where English is not the native tongue but used as an official language (Kachru 1986). As there has been little research on L2 students placed in a non-English-speaking country, Inyoung's case may shed some light on the importance of the process of choosing the SA destination. There needs to be more tailored guidelines in the program selection process. More importantly, applicants' majors and interests need to be reflected more thoroughly based on enough communication among all parties concerned before the students make their final decisions. This will help students make the most of their SA experiences.

Another finding of this study corresponding to the second research question is that the social networks the participants formed appeared to play an important role facilitating their socialization as shown in previous studies (e.g., Dewey et al. 2013; Isabelli-Garcia 2006; Yang and Kim 2011). These social networks also served as comfort zones for the students. As shown with Yujin like those students in Dewey et al. (2013) and Isabelli-Garcia (2006), being ushered into a ready-made social network right from the beginning of her SA seemed to pose a great advantage. Building a social network from scratch does take time, and considering that most exchange programs last 6 months to 
a year, SA participants do not have enough time to build one and to take full advantage of it.

It seems that a social network, which will of course change as students come and go, can indeed be passed on from one group to the next as shown with Yujin. Unlike the Korean student in the US shown in Yang and Kim (2011) or those who participated in SA programs as a group (Tanaka 2007; Tanaka and Ellis 2003), Yujin seemed very active in taking advantage of the networks, and she further developed her own networks as her SA continued. Her multiple social networking in the SA environment fostered more opportunities for interaction, which enabled a more natural use of English. It seemed that Yujin tried to "live" in the SA environment being very much engaged in the local community rather than staying peripheral as an outsider. However, both in English-speaking and in nonEnglish-speaking environments, as shown in the two cases of the present study, exchange students tend to form a community among themselves or with those sharing similar cultural backgrounds as found in Duff (2007). As was found in many previous studies (Duff 2007; Hernandez 2010; Hwang 2009; Yang and Kim 2011), opportunities to interact with local students in the SA context were not easily available. Regularly exchanging assistance between languages like English for Arabic as happened in Dewey et al. (2013) did not happen with the participants in the present study.

Kinginger (2011) illustrated that "language learning in study abroad is a dialogic and situated affair whose success depends on not only the attributes and intentions of the student but also the ways in which the student is received within his or her host community" (p. 60). Even though the present study attempted to incorporate the latter through the eyes of the participants, it was incomplete. In order to draw a complete picture, it is necessary to investigate how L2 students are perceived by the SA environments from the viewpoints of people in the SA environments and how it affects L2 students' learning trajectories.

\section{Conclusion}

Two South Korean undergraduate students' different academic study-abroad experiences were investigated. More opportunities for practicing English were available to the one in an English-speaking SA environment as opposed to the other in a non-English-speaking SA environment. Yujin at an Australian university took great advantage of social networks she established through diverse venues, which enriched her SA experience and facilitated her learning. Another finding of note is that the choice of an SA destination can have bearings on students' SA experience. Inyoung at a Finnish university was not provided with enough opportunities for communication in English, and dealing with a third language, Finnish, posed another problem for her. Even though the author attempted to describe the participants' SA experiences in as much detail as possible, analyzing their monthly reports and conducting interviews does not sufficiently gather enough in-depth information about each case.

Much research on Korean students' SA experiences has been conducted in English-speaking countries, while according to the statistics, many students also opt for programs in non-English-speaking countries for a variety of reasons. It is meaningful that the present study broadened the scope of research on SA, as it extended the context to "other" countries, but more in-depth research is needed on L2 exchange students in countries where the target language is used as a tool for education but not spoken as the L1.

Open Access This article is distributed under the terms of the Creative Commons Attribution 4.0 International License (http://creativecommons.org/licenses/by/4.0/), which permits unrestricted use, distribution, and reproduction in any medium, provided you give appropriate credit to the original author(s) and the source, provide a link to the Creative Commons license, and indicate if changes were made.

\section{References}

Ahn, S. (2014). A good learning opportunity, but is it for me? A study of Swedish students' attitudes towards exchange studies in higher education. Journal of Research in International Education, 13(2), 106-118.

Allen, L. Q. (2013). Teachers' beliefs about developing language proficiency within the context of study abroad. System, 41, $134-148$.

Batstone, R. (2002). Contexts of engagement: A discourse perspective on "intake" and "pushed output". System, 30, 1-14.

Choe, Y. H. (2013). A critical review of research on language learning abroad: Its themes and methods. English Language Teaching, 25, 1-24.

Dewey, D. P., Ring, S., Gardner, D., \& Belnap, R. K. (2013). Social network formation and development during study abroad in the Middle East. System, 41, 269-282.

Duff, P. A. (2007). Second language socialization as sociocultural theory: Insights and issues. Language Teaching, 40(4), 309-319.

Glaser, B. G., \& Strauss, A. L. (1967). The discovery of grounded theory. Chicago: Aldine.

Hernandez, T. A. (2010). The relationship among motivation, interaction, and the development of second language oral proficiency in a study-abroad context. The Modern Language Journal, 94(4), 600-617.

Hwang, S. (2009). A comparative study of English learning contexts home and abroad: Are there any communicative situations? Korean Journal of English Language and Linguistics, 9, 31-59.

Isabelli-Garcia, C. L. (2006). Study abroad social networks, motivation, and attitudes: Implications for SLA. In M. A. DuFon \& E. Churchill (Eds.), Language learners in study abroad contexts (pp. 231-258). Clevedon: Multilingual Matters. 
Kachru, B. B. (1986). The alchemy of English: The spread, function, and models in nonnative English. Oxford: Oxford University Press.

Kang, D. M. (2014). The effects of study-abroad experiences on EFL learners' willingness to communicate, speaking abilities, and participation in classroom interaction. System, 42, 319-332.

Kinginger, C. (2011). Enhancing language learning in study abroad. Annual Review of Applied Linguistics, 31, 58-73.

Lave, J., \& Wenger, E. (1991). Situated learning: Legitimate peripheral participation. Cambridge: Cambridge University Press.

Magnan, S. S., \& Back, M. (2007). Social interaction and linguistic gain during study abroad. Foreign Language Annals, 40, 43-60.

Merriam, S. B. (1998). Qualitative research and case study application in education. San Francisco: Jossey-Bass.

Mora, J. C., \& Valls-Ferrer, M. (2012). Oral fluency, accuracy and complexity in formal instruction and study abroad learning contexts. TESOL Quarterly, 46(4), 610-641.

Sasaki, M. (2007). Effects of study-abroad experiences on EFL writers: A multiple-data analysis. The Modern Language Journal, 91(4), 602-620.

Segalowitz, N., \& Freed, B. (2004). Context, contact, and cognition in oral fluency acquisition: Learning Spanish in at home and study abroad contexts. Studies in Second Language Acquisition, 26, 173-199.

Shvidko, E., Evans, N. W., \& Hartshorn, K. J. (2015). Factors affecting language use outside the ESL classroom: Student perspectives. System, 51, 11-27.

Stake, R. E. (1995). The art of case study research. Thousand Oaks: Sage Publications.

Statistics Korea. (2015). Students studying abroad. http://www.index. go.kr/potal/main/EachDtlPageDetail.do?idx_cd=1534. Accessed 20 Sep 2016.

Tanaka, K. (2007). Japanese students' contacts with English outside the classroom during study abroad. New Zealand Studies in Applied Linguistics, 13, 36-54.

Tanaka, K., \& Ellis, R. (2003). Study-abroad, language proficiency, and learner beliefs about language learning. JALT Journal, 25(1), 63-84.

Thompson, A. S., \& Lee, J. (2014). The impact of experience abroad and language proficiency on language learning anxiety. TESOL Quarterly, 48(2), 252-274.

Wenger, E. (1998). Communities of practice: Learning, meaning, and identity. Cambridge: Cambridge University Press.

Yang, J. S., \& Kim, T. Y. (2011). Sociocultural analysis of second language learner beliefs: a qualitative case study of two studyabroad ESL learners. System, 39, 325-334. 